\title{
A Rare Case of Multiple Epidermal Cyst Scrotum and Its Excision Under Spermatic Cord Block Obviating Spinal Or General Anaesthesia Need
}

\section{Shruti Patel, Naveen Kumar*}

Department of Plastic Surgery, Lady Hardinge Medical College and Associated Hospital, New Delhi -110001.

Correspondence to: Naveen Kumar, Department of Plastic Surgery, Lady Hardinge Medical College and Associated Hospital, New Delhi -110001.

Received date: September 03, 2021; Accepted date: September 18, 2021; Published date: September 25, 2021

Citation: Patel S, Kumar N (2021) A Rare Case of Multiple Epidermal Cyst Scrotum and Its Excision Under Spermatic Cord Block Obviating Spinal Or General Anaesthesia Need. J Med Res Surg 2(S1): pp. 1-2. doi: 10.52916/jmrs21S102

Copyright: (C2021 Patel S, et al. This is an open-access article distributed under the terms of the Creative Commons Attribution License, which permits unrestricted use, distribution and reproduction in any medium, provided the original author and source are credited.

\section{ABSTRACT}

Epidermal cysts are the most common epithelial cysts usually with non malignant potential. These occur commonly in hair- bearing areas mostly on the scalp, also on the face, neck, back, and scrotum. Etiology is usually unknown. It can be seen commonly in individuals with history of significant Acne vulgaris. Multiple sebaceous cysts over the scrotum is a rare condition. Only eight cases of multiple epidermal cysts in scrotum have been reported so far from India in the past literature. This condition is usually asymptomatic and painless. It may turn painful if gets infected and often may be associated with discharge of pus.

We present a rare case of multiple epidermal cysts of scrotum in a 36 year old patient which was managed with complete excision of the cysts done under local anesthesia followed by primary closure with better outcome in cosmesis taking care of not to jeopardize the vascular supply to local flaps and testis.

\section{Keywords:}

Cyst, Scrotum, Epidermal, Excision, Multiple

\section{Introduction}

Epidermal cysts are the most common epithelial cysts usually with non malignant potential. These occur commonly in hairbearing areas mostly on the scalp, also on the face, neck, back, and scrotum [1]. On histopathological examination, these are well encapsulated having cystic lining of stratified squamous epithelial cells with no cutaneous adnexal structures within the stromal tissue [2]. It results from ductal obstruction of sebaceous gland in the hair follicles leading to the accumulation of sebum along with other keratinous masses. Etiology is usually unknown. It can be seen commonly in individuals with history of significant Acne vulgaris. Multiple sebaceous cysts over the scrotum is a rare condition. Only eight cases of multiple epidermal cysts in scrotum have been reported so far from India in the past literature. This condition is usually asymptomatic and painless. It may turn painful if gets infected and often may be associated with discharge of pus. Multiple sebaceous cyst may be associated with Gardner syndrome though rare but it should also be ruled out [3].

The gold standard treatment for epidermal cyst is complete excision of sac and its contents [4]. Multiple sebaceous cysts over the scrotum are a rare condition but should be promptly treated if infected to avoid possible fatal consequences such as Fournier's gangrene, a type of necrotising fasciitis, normally occurring in older men [3].

There may be the evidence of scrotal calcinosis via dystrophic calcification in case of multiple scrotal cysts [2]. There are evidences that basal cell Carcinoma or squamous cell Carcinoma may develop within an epidermal cyst but as a very rare event [1]. The first case of the epidermoid cyst was reported by Dockerty and prestly in 1942 [5]. We present a rare case of multiple epidermal cysts of scrotum which was managed with complete excision of the cysts done under local anesthesia followed by primary closure with better outcome in cosmesis taking care of not to jeopardize the vascular supply to local flaps and testis.

\section{Case Presentaion}

A 36-year-old male patient presented to the Plastic surgery department with chief complaints of multiple painless cystic swellings over scrotum for last 5 years (Figure 1 and 2).

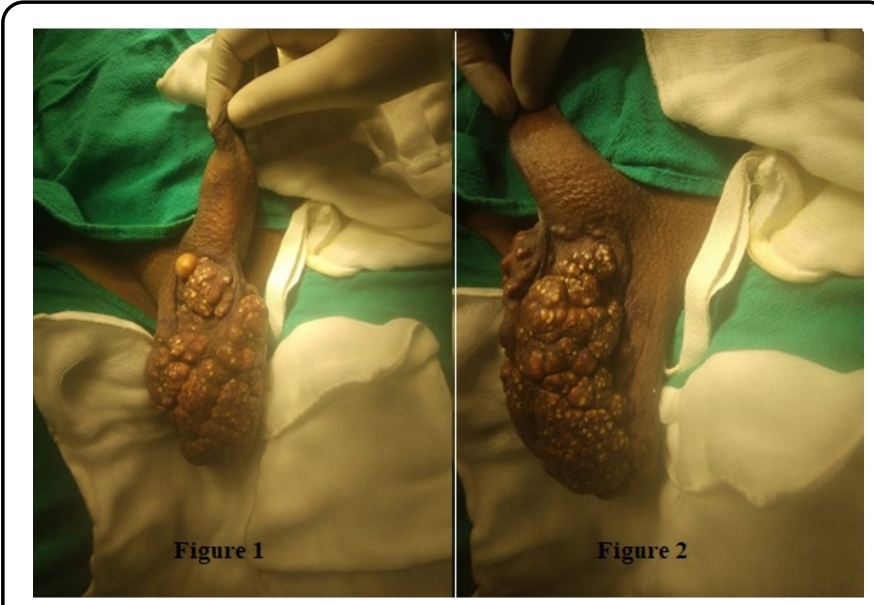

Figure 1 and 2: Preoperative images of the patient.

On local examination, multiple non-tender cystic swellings were found in the scrotal skin, which were firm in consistency. Based upon the clinical findings, a diagnosis of multiple epidermal cysts of scrotum was made and the patient was advised for surgery. Surgery was planned under bilateral spermatic cords block anaesthesia. Complete excision of scrotal skin with all the cystic swellings was done followed by primary closure of mobilized local flaps (Figure 3) after the testes were placed 
inside the created subdartos pouch which was then sutured at lower end to prevent the torsion and specimen was sent for histopathological examination.

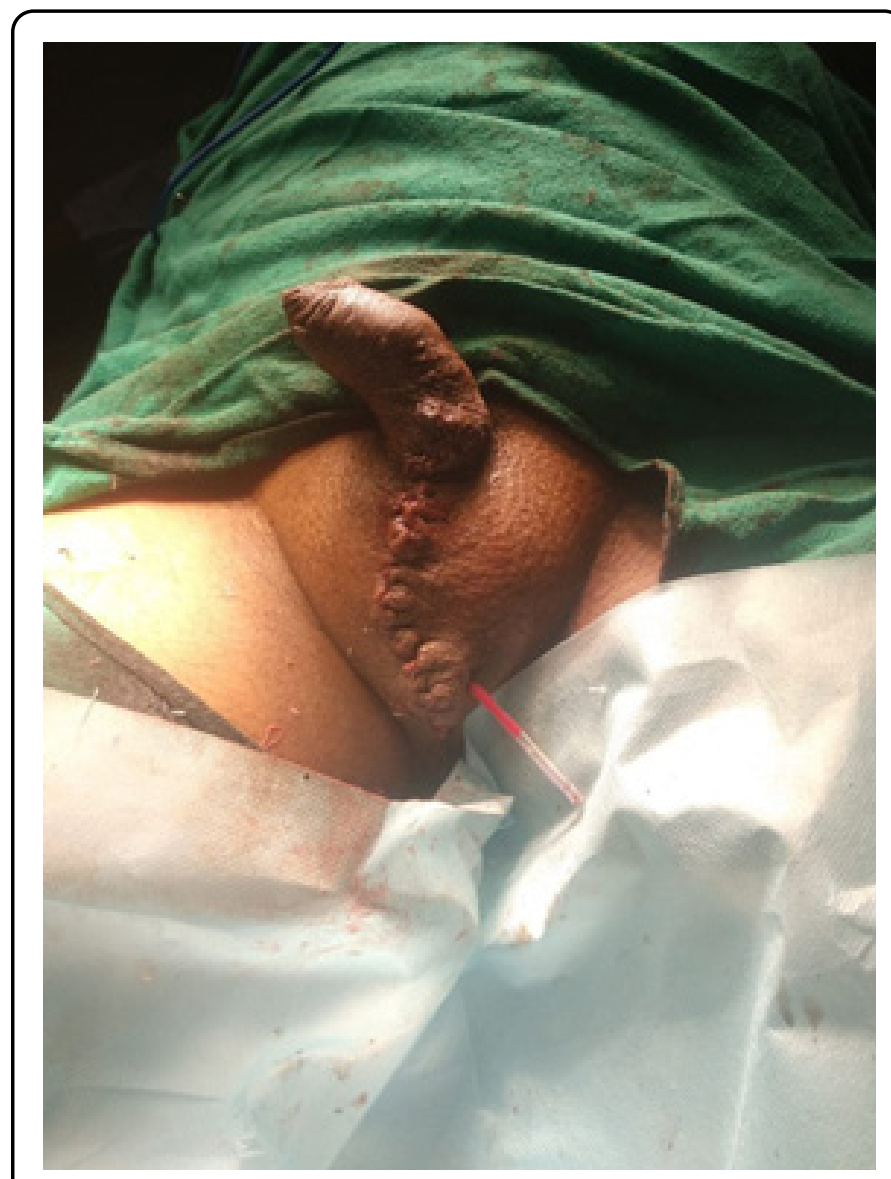

Figure 3: Following complete excision of the scrotal skin with cyst.

The pathology revealed epidermal cysts lined by stratified squamous epithelium and contain loosely packed keratin debris and cholesterol with multifocal calcifications. Postoperative period was uneventful (Figure 4) and the patient recovered well with no recurrence after 8 months of follow-up.

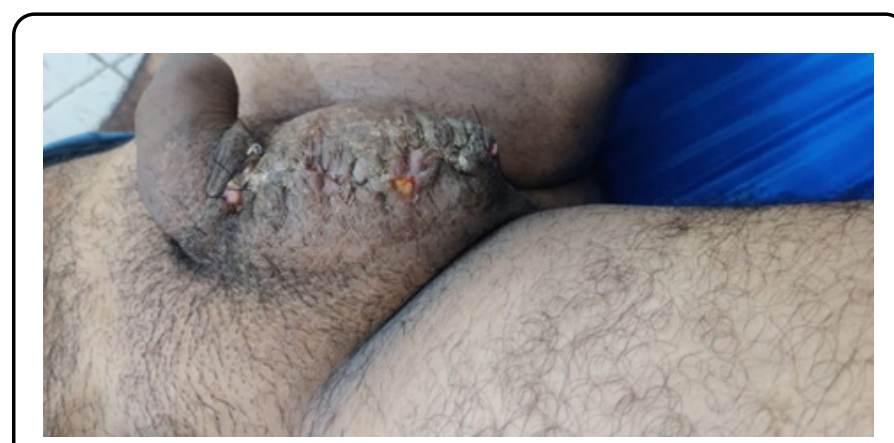

Figure 4: Post-operative follow up image.

\section{Discussion}

An epidermal cyst is described as a small, dome-shaped cyst that develops in the skin, filled with a thick, greasy, cheese like substance [6]. The pathogenesis of the epidermal cyst is usually not known, different theories related to the embryonic origin of this lesion have been described [7]. It was suggested that they arise from the ectopic cutaneous tissue due to a traumatic implantation of the epidermal tissue in to the dermis and the subcutis. However, in the case of the extra-testicular scrotal epidermal cyst, these are believed to occur secondary to abnormal closure or the associated degenerative process of the median raphe and the urethral groove $[8,9]$. A complete removal of the cyst is the only choice of treatment for epidermal cyst of scrotum.

Cannistra C, et al. [3] used the technique of pedicle inguinal flap for the reconstruction of the scrotum. Here, in this case we did the complete excision of the affected scrotal skin taking care not injure the underlying testis and the primary closure after securing the testes in subdartos pouch were done in conformity with better aesthetic outcome. This is the only case reported so far in the literature which was performed under spermatic cord block thereby avoiding the need of spinal or general anaesthesia.

\section{Conclusion}

Multiple epidermal cysts scrotum is a rare condition and its complete excision is possible under spermatic cord block thereby obviating the spinal or general anesthesia need.

\section{Decalaration}

The study is in accordance with the ethical standards of the responsible committee on human experimentation (institutional or regional) and with the helsinki declaration of 1975, as revised in 2000 .

\section{Consent to Participate}

Duly informed consent was obtained in all the cases.

\section{Conflict of Interests}

The authors declare that they have no competing interests.

\section{References}

1. Mohite P, Bhatnagar A (2006) A case of multiple sebaceous cysts over scrotum in a 35 years old male. Internet J Surg 9(1): pp. 1-4.

2. Bolognia JL, Jorizzo JL, Schaffer JV (2012) eds. Dermatology, 3rd ed. Philadelphia, Pa: Mosby Elsevier; Chapter 37: pp. 18171827.

3. Cannistra C, Kirsch-Noir F, Delmas V, et al. (2003) Scrotal reconstruction by inguinal flap after Fournier's gangrene. Prog Urol 13(4): pp. 703-7066.

4. Klin B, Ashkenazi H (1990) Sebaceous cyst excision with minimal surgery. Am Family Phys 41: pp. 1746-1748.

5. Yeshwant Kumar NNT, Reshma S, Deivanayagam S (2017) Multiple epidermal cysts of the scrotum: a rare case report. Int Surg J 4(7): pp. 2375-2376.

6. Cruz AB, Aust JB (1983) Lesions of the skin and subcutaneous tissue. In: Hardy JD, Kukora JS, Pass HI, eds. Hardy's Textbook of surgery. Philadelphia: Lippincott: pp. 319-328.

7. Tanaka T, Yasumoto R, Kawano M (2000) Epidermoid cyst arising from the spermatic cord area. Int J Urol 7(7): pp. 277279.

8. Katergiannakis $\mathrm{V}$, Lagoudianakis EE, Markogiannakis $\mathrm{H}$, et al. (2006) Huge epidermoid cyst of the spermatic cord in an adult patient. Int J Urol 13(1): pp. 95-97.

9. Picano-Neto JM, Lipay MA, D’Avila CL, et al. (1997) Intrascrotal epidermoid cyst with extension to the rectum wall: a case report. J Pediatr Surg 32(5): pp. 766-767. 